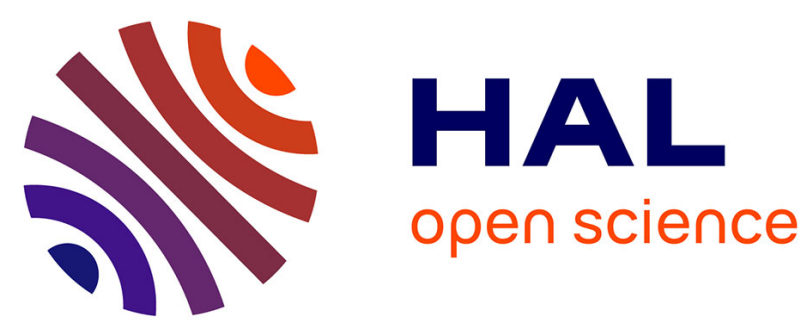

\title{
A DATA-AND KNOWLEDGE-DRIVEN METHODOLOGY FOR GENERATING ECO-INDUSTRIAL PARK ARCHITECTURES
}

Andreas Makoto Hein, Marija Jankovic, Romain Farel, Bernard Yannou

\section{- To cite this version:}

Andreas Makoto Hein, Marija Jankovic, Romain Farel, Bernard Yannou. A DATA-AND KNOWLEDGE-DRIVEN METHODOLOGY FOR GENERATING ECO-INDUSTRIAL PARK ARCHITECTURES. ASME 2016 International Design Engineering Technical Conferences and Computer and Information in Engineering Conference (IDETC/CIE 2016), Aug 2016, Charlotte, NC, United States. hal-01363586

\author{
HAL Id: hal-01363586 \\ https://hal.science/hal-01363586
}

Submitted on 12 Sep 2016

HAL is a multi-disciplinary open access archive for the deposit and dissemination of scientific research documents, whether they are published or not. The documents may come from teaching and research institutions in France or abroad, or from public or private research centers.
L'archive ouverte pluridisciplinaire HAL, est destinée au dépôt et à la diffusion de documents scientifiques de niveau recherche, publiés ou non, émanant des établissements d'enseignement et de recherche français ou étrangers, des laboratoires publics ou privés. 


\title{
A DATA- AND KNOWLEDGE-DRIVEN METHODOLOGY FOR GENERATING ECO- INDUSTRIAL PARK ARCHITECTURES
}

\author{
Andreas M. Hein \\ Laboratoire Genie Industriel, CentraleSupélec, \\ Université Paris-Saclay ${ }^{1}$, \\ Châtenay-Malabry, Paris region, France / \\ Paris-Saclay Energy Efficiency (PS2E), \\ Loges en Josas, Paris region, \\ France \\ Romain Farel \\ Paris-Saclay Energy Efficiency (PS2E), \\ Loges en Josas, Paris region, \\ France
}

\author{
Marija Jankovic \\ Laboratoire Genie Industriel, CentraleSupélec, \\ Université Paris-Saclay, \\ Châtenay-Malabry, Paris region, France
}

\begin{abstract}
Industrial symbiosis can be understood as the substitution of new resources used in an industrial process by another resource that would otherwise be discarded. Industrial symbiosis can thereby create new revenue streams and at the same time reduce environmental impact. The initial step in creating an industrial symbiosis is the identification of potential substation relationships between production plants. This step is challenging, as information about the companies is often not available. Several software tools have been developed in order to identify potential symbiosis opportunities. However, these tools have the shortcoming that they require extensive data input from companies owning the production plants. This requirement limits the number of companies for which symbiosis opportunities are identified. In this paper, we propose a data-driven methodology for identifying industrial symbiosis and generating eco-industrial park architectures. The methodology is based on meta-models of industrial plants for identifying plant attributes for certain types of plants, correlations that estimate the rough amount of resource supply and demand of a plant, and a rulebased system that identifies symbiosis opportunities based on knowledge from successful symbioses. Based on the symbiosis opportunities, approach generates eco-industrial park architectures that are optimal in terms of economic and environmental performance. Finally, we apply the methodology to a case study of the existing Kalundborg eco-industrial park to evaluate if the methodology is capable of finding existing symbioses. We conclude that the methodology can be applied to screening industrial zones with standard types of industrial plants. However, the results depend on the types of existing industrial plant meta-models in the database. Future work will focus on extending the data and knowledge base; and validating the methodology by its application to other existing eco-industrial parks.
\end{abstract}

\section{INTRODUCTION}

An industrial park can be defined as a set of businesses

within a specific geographic area which share resources and thereby increase profitability, reduce environmental impact, and improve social performance (Lowe, 2001). An industrial symbiosis can be defined as "a flow of underutilised resource(s) (comprising substances and/or objects and/or energy), from an entity which would otherwise discard them, to another entity which uses them as a substitute for new resources. " (Deutz, 2014) An example for an industrial symbiosis is the use of waste cooling water from a refinery as cooling water for a power plant, depicted in Fig. 1 adapted from (Gertler, 1995). Without this symbiosis, the power plant would use more expensive surface water from a lake. The refinery saves the cost of constructing waste water treatment facilities and receives revenues for the waste water. The underutilized resource is therefore waste water. Without the symbiosis, it would be discarded and not further used. The power plant would use a new resource, the lake water. By establishing an industrial symbiosis, both symbiosis partners save costs and resources.

\footnotetext{
${ }^{1}$ Formerly Laboratoire Genie Industriel, École Centrale Paris
} 


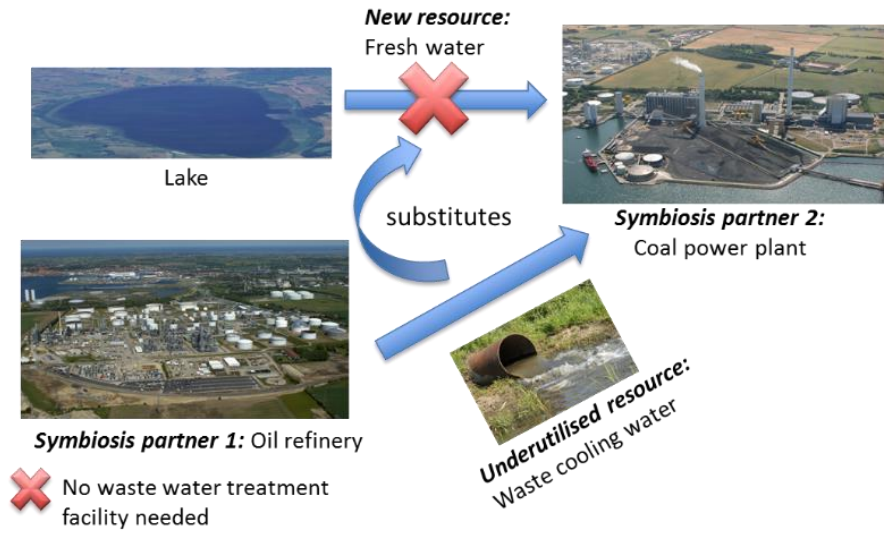

Fig. 1: Waste water-based symbiosis at Kalundborg

Industrial symbioses play an important role in eco-industrial parks. An eco-industrial park is a set of businesses that share resources in order to increase profitability and reduce environmental impact (Lowe, 2001). The most famous eco-industrial park is located at Kalundborg in Denmark. Over 40 different symbioses have reduced CO2 emission by about $8 \%$ and are saving three million tons of water per year (Chertow, M. R., Lombardi, 2005; Hodge et al., 2010; Jacobsen, 2006; Korhonen and Snäkin, 2005; Sokka, 2011; Tian and Zelkowitz, 1992). The waste water symbiosis in Fig. 1 is an existing symbiosis within the Kalundborg eco-industrial park.

\section{STATE OF THE ART: SYMBIOSIS DEVELOPMENT}

Industrial symbioses allow for improving profitability and reducing environmental impact, hence, "killing two birds with one stone". How can we then develop industrial symbioses? (Grant and Seager, 2010) divides the symbiosis development process into five steps. The process starts with opportunity identification, continues with opportunity assessment, barrier removal, commercialization and adaptive management; and finally documentation, review, and publication. In the following, we will mainly deal with the "opportunity identification" and the "opportunity assessment" step, as we are interested in the initial stage of symbiosis development.

According to (Grant and Seager, 2010), the step "opportunity identification" consists of three sub-steps:

- New process discovery: A new process for transforming a waste / by-product into a useful resource,

- Input-output matching: Finding a company that can supply a resource and a company that needs that resource,

- Case study mimicking: Involves "mimicking successful relationships employed by similar organizations." (Grant \& Seager, 2010, p.745).

One of the challenges in designing an industrial symbiosis is to find options and stakeholders for flow exchange. From the literature and an interview with a business developer at the eco-industrial park of Kalundborg, we identify three approaches to search for industrial symbiosis opportunities (Boons and Spekkink, 2012):

- Matchmaking events: Workshops and brainstorming sessions where representatives of industrial plants are searching for symbiosis opportunities. Such events are important for fostering mutual trust and confidence between potential symbiosis partners. Furthermore, companies usually share some data about their plant to facilitate finding symbiosis opportunities.

- Business associations: Associations where representatives of local businesses meet on a regular basis. These meetings are also used for sharing waste supply and resource demand information. On that basis, symbiosis opportunities can emerge.

- Third-parties: consultancies, non-profits, public agencies. These actors identify symbiosis opportunities and encourage companies to get into contact and assess the symbiosis opportunity. Government agencies and public funds sometimes provide funds for pursuing symbiosis feasibility studies. (Information from interview with business developer at Kalundborg.)

As this list of approaches shows, the social element is very important before potential future symbiosis partners invest in feasibility studies etc. However, participants of matchmaking events and business associations do not know a priori about the likelihood that their plant could participate in a symbiosis. If companies do not participate in such events and share data, they do not know if there is a symbiosis opportunity for them. This becomes a serious problem for large industrial parks with hundreds of companies and industrial parks where the three approaches for identifying symbiosis opportunities are currently not present. In the following, we conduct a literature survey of existing tools and methods for identifying symbiosis opportunities. We are, in particular, interested in approaches that can be used even before extensive data from companies has been acquired. 
A number of symbiosis development support tools and methods have been developed in the past. Recent examples are the French Presteo tool (Julien-Saint-Amand and Le Moenner, 2008), the Swiss symbiosis identification methodology (Massard and Erkman, 2007), and the e-Symbiosis tool by (Cecelja et al., 2015). Several shortcomings exist that provide research opportunities. First, almost all tools focus on the technical aspects of symbiosis identification step. There are only few tools that include or focus on the symbiosis assessment step. Regarding the assessment step, metrics such as capital expenditures and operation / maintenance cost are usually included such as in (Schulze, 2014). To the knowledge of the authors, no tool uses more sophisticated techno-economic analysis approaches such as discounted cash flow.

Another shortcoming of existing tools is the analysis of environmental benefits. One of the most common environmental performance approaches is life-cycle assessment (LCA). DIME proposed a LCA approach which was not realized. RUES provides logical rules for environmental screening. DIET claims to optimize economic, environmental, employment objectives. However, although economic, environmental, and societal assessment of symbiosis has been touched, with the rapid advance of LCA research and application in recent years, the environmental assessment is likely to be outdated. As (Zamagni et al., 2012) argues, LCA standardization efforts and the emergence of new types of LCA such as consequential LCA open up new possibilities for the assessment of industrial symbioses.

Another area that advanced in recent years is the development of taxonomies for wastes and resources. The European Waste Catalogue and the UN Product Catalogue provide extensive categories for wastes and products for various industrial activities. Such standardized representations can bridge the semantic gap between inputs and outputs from the tools and the understanding of users, as both can "speak the same language" (Hein, 2010). Most tools except for IUWAWM and Presteo do not use any standardized waste taxonomy. However, Presteo does not use any matching system. IUWAWM needs input from each actor before it can start searching for matches.

Finally, all of these tools require extensive input from the companies themselves in order to produce results. The data is either directly fed into the system by companies or by the organization using the tool. None of the tools and methods can be used in a situation where no proprietary data of companies is available. In the next step, we will illustrate that there is a real need for performing such "a priori" analysis of industrial zones, based on publicly available data only.

\section{PROBLEM STATEMENT}

Fig. 2 shows the industrial zone of Le Havre in France. There is an interest from local companies and government to convert the zone into an eco-industrial park. The zone consists of at least 114 industrial plants. ${ }^{2}$ Commonly each industrial plant consist of dozens to hundreds of inputs and outputs. On average, one industrial plant has about 20 inputs and outputs. ${ }^{1}$ This means that there are over 2000 outputs that can be matched with 2000 inputs. In total, these are over 4 million potential input - output matches that need to be assessed. It is clear that such a matching cannot be done manually. Within the industrial zone, symbiosis opportunities are currently identified ad-hoc and opportunistically. Furthermore, the assessment of an opportunity is costly and time-consuming. It took one person about a half a year to assess the feasibility of one potential industrial symbiosis. As it is impossible to collect detailed data for each plant and doing feasibility studies for each symbiosis opportunity, the question is how to perform an automatic screening of the industrial zone for symbiosis opportunities without extensive data collection?

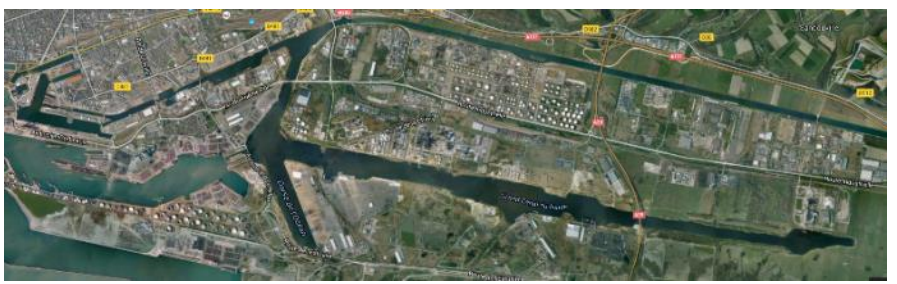

Fig. 2: Aerial view of the French port industrial zone of Le Havre (Google Maps)

This paper presents a methodology for identifying industrial symbiosis opportunities within large industrial zones before extensive data collection is required. Such a methodology would allow for pre-selecting companies that are likely to form symbioses and concentrate the matchmaking efforts on them.

\section{OBJECTIVES}

Based upon previously identified research gaps, the following objectives for an eco-industrial park architecting methodology can be formulated:

- Screen large numbers of industrial plants and their input/outputs to form symbioses automatically;

- Identify technologies for converting a specific waste into a resource automatically;

- Perform screening under incomplete information: Oudalle

${ }^{2}$ Number calculated by using data from the „Installations Classées“ data base for five communities: Le Havre, Sandouville, Gonfreville-1’Orcher, Rogerville, 
Known: Type of business, size, types of wastes

Unknowns: Quantities of resources and wastes

\section{Output:}

A set of symbioses that are likely to be successful individually and collectively, forming the basis of an eco-industrial park architecture, i.e. a set of waste / resource exchanges and their associated technologies.

The reason for not having a list of individual symbioses as the main output of the methodology, is that a single symbiosis is subject to fewer constraints than a set of symbioses. For example, a set of symbioses is constrained by the resources available that can be supplied to another industrial plant. Hence, the number of symbioses one industrial plant can engage in is limited.

Fig 3 shows the main input and output of the eco-industrial park architecting methodology. The main input from the user is data from publicly available databases for a specific industrial zone. Ideally, the data can be fed into the system automatically. One of the most comprehensive databases for industrial plants in France is the "Base des Installations Classées" (Inspection des Installations Classées, 2015). It is a database of all "classified" industrial installations in France. All permits for hazardous substances and environmental emissions with higher limits are registered. In many cases, some of the data can be used to estimate the dimensions of the industrial plant. Furthermore, the database contains the geographic locations of the plants. The geography and topology of the site can be easily looked up via Google Earth or other geo-information systems (GIS). Fig. 3 also shows the main output: about 5-10 ecoindustrial park architectures. What is an "architecture" that is generated? It is a set of industrial plants and a set of symbioses they take part in. The symbioses are represented in terms of the waste supply, the symbiosis infrastructure that transports the waste, technologies that convert the waste into a resource, and an estimate of the quantity for the waste and resource.

Why 5-10 architectures? This number is usually associated with the number of alternatives a decision-makers can properly take into account. This result has been confirmed in the literature on cognitive psychology and conceptual design and systems architecting literature (Condat et al., 2012; Miller, 1956). These architectures have been selected based upon the likelihood that they can be realized. The criteria include strategic considerations such as competition between companies, past instances where two types of companies have formed a symbiosis, technological criteria such as technological maturity, economic criteria, and environmental criteria. Societal criteria are currently not included.

In the next step, we propose a methodology that addresses the research gaps and is, at this stage, focusing on creating an ecoindustrial park from an existing industrial zone.

\section{A NEW METHODOLOGY FOR INDUSTRIAL SYMBIO-SIS IDENTIFICATION}

We introduce a methodology for identifying industrial symbioses and generating eco-industrial park architectures a priori, before extensive data needs to be collected from individual companies. Fig. 3 shows an overview of the steps in the methodology. At this point, we consider an existing industrial zone, but the methodology can be easily extended to developing an eco-industrial park on a "green field". The "green field" case is currently not considered, as the main use case in France is the conversion of an existing industrial zone into an eco-industrial park. The conversion may include the construction of new industrial plants within the zone such as incinerators and power plants. Hence, the focus of this methodology is on the conversion of an existing industrial zone.

The first step is the creation of a model of the industrial zone under consideration. For properly dimensioning the industrial plants within the zone, publicly available data is used. This data is fed into a number of correlations that are used for estimating the main inputs and outputs of the industrial plant from the publicly available data. These estimates from the correlations are then stored in instances of industrial plant meta-models. The meta-models are "templates" that list the major inputs and outputs of certain types of plants. The model of the industrial zone includes models of the plants with their input and output estimates as well as their location within the industrial zone. Other infrastructure elements such as roads are neglected at this point. 


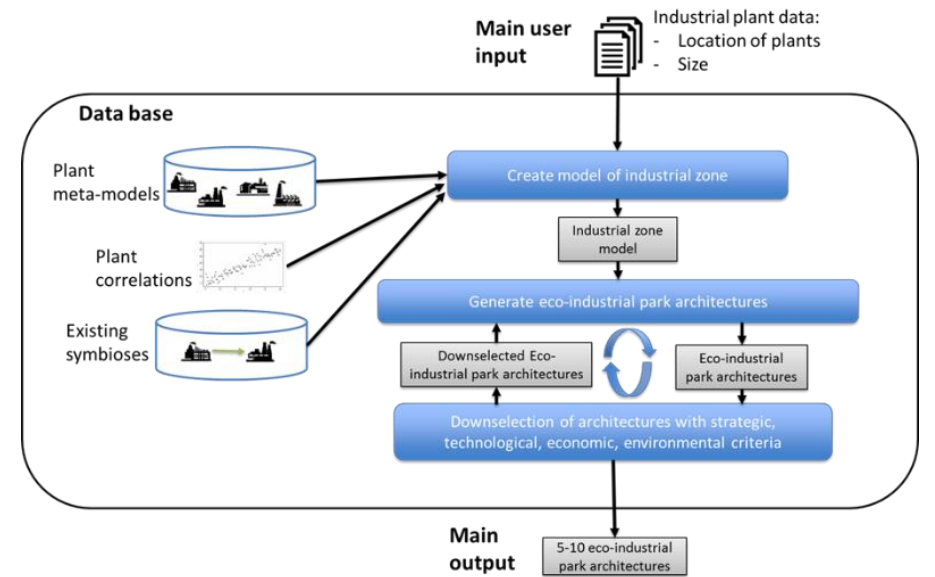

Fig. 3: Overview of methodology steps

In the second step, eco-industrial park architectures are generated. The generated architectures are continuously down-selected by using strategic, technological, economic, and environmental criteria into consideration. First, strategic criteria are taken into consideration such as competition between companies. Companies that are in competition usually do not engage in symbioses. For these companies, no further assessment of symbioses needs to be performed. In the next step, technologies that are used for the symbiosis infrastructure are assessed under criteria such as technological maturity. For example, if only technologies with a Technology Readiness Level (TRL) of 9 should be considered, i.e. technologies that are already in operational use, all other technology options are excluded. Then, economic feasibility is assessed, using classic approaches of techno-economic analysis. As a last step, environmental assessment is conducted. It is currently based on a waste reduction and resource substitution metric but we intend to adapt a Life Cycle Analysis (LCA) to this step in the future. In case the number of eco-industrial park architectures after this step is still larger than 10, architectures that are similar to other architectures are eliminated. The objective is to provide the decision-maker with a variety of "good" solutions (Condat et al., 2012). Performing these steps will lead to the desired output of 5-10 eco-industrial park architectures.

\section{MODEL OF INDUSTRIAL ZONE}

The methodology needs to identify potential symbiosis opportunities before extensive data is collected. More specifically, we want to avoid the high costs associated with data collection such as conducting audits and interviews. By contrast, if we can find publicly available data bases from where data can be extracted, this would circumvent this issue. However, one of the problems with these databases is that they usually do not contain data of all resource inputs and waste outputs. For example, one French data base of registered industrial installations only contains data on hazardous materials and emissions a plant is allowed to release into the environment or stores on its territory. To circumvent the lack of resource and waste data, the idea is to use the publicly available data and to estimate the resource inputs and waste outputs using correlations. Fig. 4 provides an overview of the proposed estimation approach. For estimating the plant characteristics we want to know, we use correlations and plant meta-models. The correlations establish a link between a parameter that is based on publicly available data and a parameter that is known to be associated with a certain type of plant. By using correlations, we can infer with a certain likelihood the value for that parameter for a specific plant using regression analysis. What we also need to know is which parameters are key for specific types of plants in order to link the parameters of the correlation with the key plant parameters. This is established by so-called plant meta-models, which were introduced in (Hein et al., 2015a, 2015b). The plant meta-models are therefore a priori classifications of a certain plant within an industrial zone. As the classification is a priori, there is a certain likelihood that the plant does not correspond to the meta-model in reality. In such a case, the data can be updated and the methodology reapplied. The proposed inference approach therefore allows for estimating the plant types within an industrial zone and the associated resource inputs and waste outputs. In the next step, we describe how eco-industrial park architectures can be generated based on this industrial zone model. 


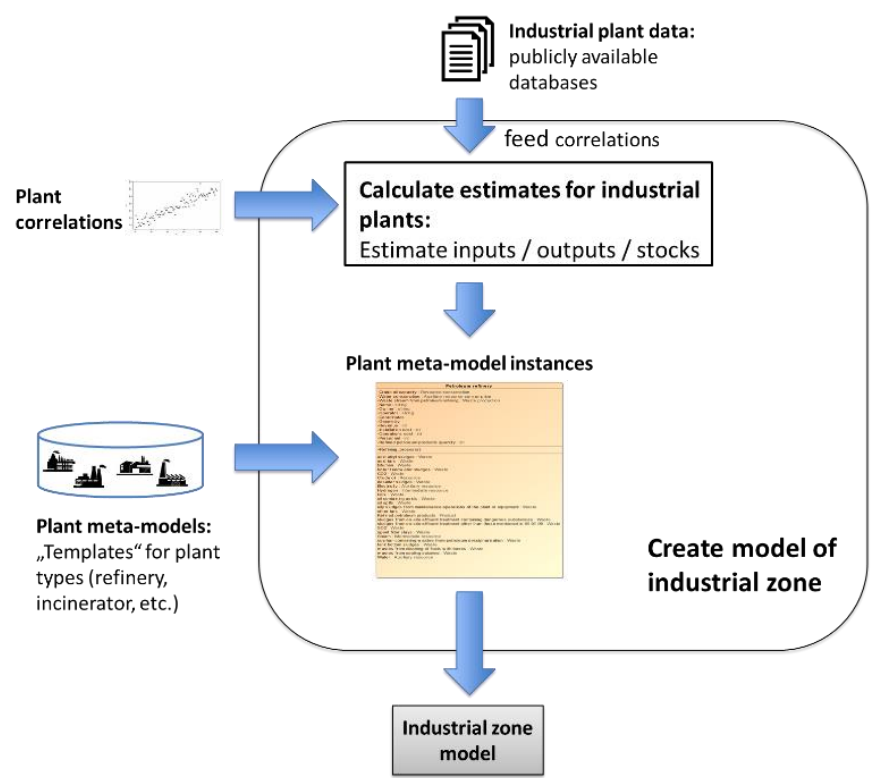

Fig. 4: Industrial zone model generation step

\section{GENERATE ECO-INDUSTRIAL PARK ARCHITEC-TURES}

The eco-industrial park architecture generation step consists of two sub-steps. In the first sub-step, resource inputs and waste outputs of the plants and urban areas in an industrial zone are matched according to a set of rules. Based on these matches, actual eco-industrial park architectures are generated in the second sub-step. This includes the assignment of technologies that realize the exchange of wastes for substituting for resources and creating a set of potentially feasible symbioses taking demand / supply constraints into consideration.

\section{RULE-BASED MATCHING}

For finding waste - resource matches between industrial plants and municipalities, we use a rule-based matching system. A rulebased matching system includes a set of logical rules of the form "if A then B". These rules are then applied to a set of facts, which is in our case the model of the industrial zone. The inference engine checks if the conditions for applying a rule are met, for example if A is present. If yes, the rule infers B from A. Rule-based systems are also called "expert systems" as they model the way experts think for reaching conclusions. We developed a rule-based system that is implemented in Prolog and contains four types of rules:

Process knowledge-based rules: Based on knowledge on processes in certain types of plants, resource inputs and waste outputs are inferred. Publicly available process data is used, such as from (Brown, 1996). For example, the process for producing hydraulic cement requires clinker, water, electricity, limestone, clay, and shale. Fig. 5 shows the general structure of the substitution rule. The rule-based system has stored numerous substitution rules, based on process knowledge for types of wastes and resources. If the rule-based system detects a pattern for an instance that corresponds to a rule, it creates a substitution relationship between the waste and resource instance.

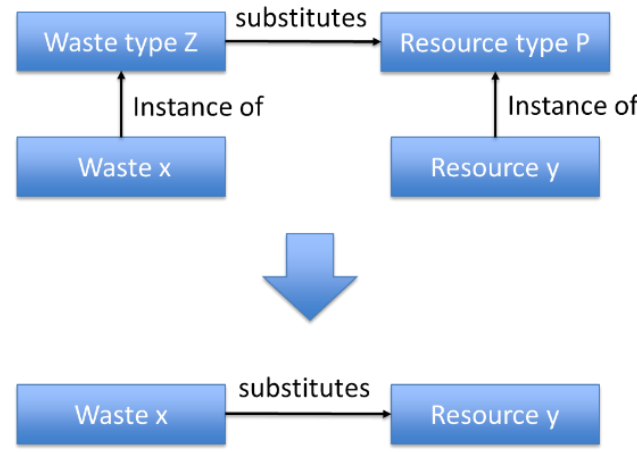

Fig. 5: Visualization of the substitution rule

Rules based on existing symbioses: If a symbiosis between two types of actors and a resource has already been established somewhere, there is a higher likelihood that such a symbiosis can be created again, as it seems to be in principle feasible. We use a database at the Paris-Saclay Efficacité Énergétique (PS2E) institute with more than 200 symbioses compiled from various sources that 
include the type of actors taking part in the symbiosis and the transferred resource. Table 1 shows the material / energy flows between two types of actors and their occurrence in the database. If a plant of type A supplied resource type 1 to a plant of type B, then the instance of type A and an instance of type B can supply an instance of resource of type 1.

\section{Table 1: Most frequent symbiosis partners and resources in 14 eco-industrial parks}



Taxonomy-based rules: We use waste and resource taxonomies based on the EU Waste Catalogue and the United Nations' "International Standard Industrial Classification of All Economic Activities (ISIC)" to define several abstraction levels for wastes and resources. These abstraction levels allow for dealing with epistemic uncertainty regarding the waste and resources of a specific actor within an industrial zone. For example, we know that a refinery generates large quantities of waste water but the amount of pollutants in the water and their composition differs from refinery to refinery. Although we do not know about the exact composition, we may still classify the generated waste water as "waste water". When more accurate data is available, we may find out that the waste water cannot be used for a certain symbiosis. Depending on the degree of epistemic uncertainty, we assign a higher or lower likelihood that a symbiosis can materialize.

Compositional rules: Waste flows and resources often consist of components, which can be matched individually. For example, natural gas consists to a large degree of methane. Hence, finding out that both contain methane can open up an opportunity for symbiosis. Another example is fly ash from incineration processes. The fly ash contain a certain amount of precious metals such as nickel and vanadium. Fig. 6 shows a visualization of the compositional rule. The rule base contains a number of component types for waste and resource types. If the rule-based system detects a certain waste or resource instance that has a component in common, it will create a substitution relationship between these instances.

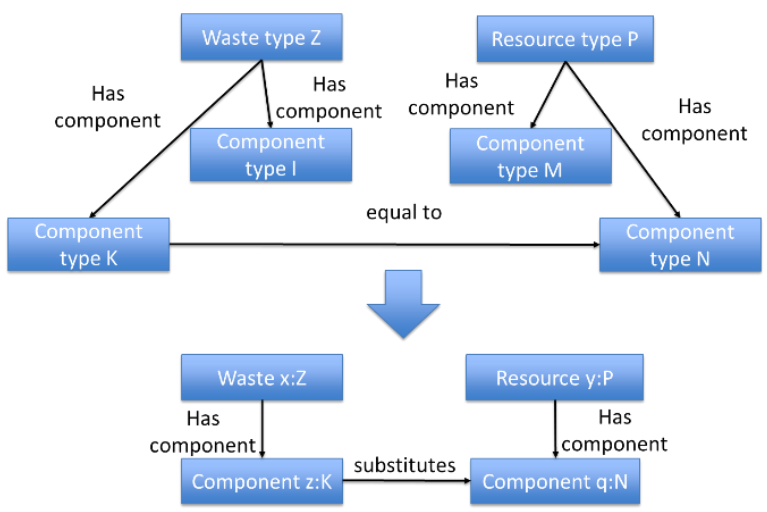

Fig. 6: Visualization of the compositional rule

With all these rules, we need an approach to calculate an aggregate likelihood value for symbioses. For this purpose, we use an evidence scoring approach.

$E_{\text {score }}=w_{1} E_{\text {existing }}+w_{2} E_{\text {process }}+w_{3} E_{\text {tax_dist }}+w_{4} E_{\text {comp }}$

with $\sum_{i=1}^{4} w_{i}=1$ 
$w_{i}$ is a weighting factor, $E_{\text {existing }}$ the score for a similar, existing symbiosis, $E_{\text {process }}$ the score for a known process, $E_{\text {tax_dist }}$ is a score for the closeness of two waste / resource within a taxonomy, $E_{\text {comp }}$ is the similarity of waste / resource in terms of its composition. $E_{\text {existing }}$ is a binary variable. If two types of plants have already engaged in a symbiosis based on a waste / resource, $E_{\text {existing }}$ is 1 , if not, it is $0 . E_{\text {process }}$ is also binary. If a plant type needs a resource and a waste, according to a data base, $E_{\text {process }}$ is set to 1 . If the waste or resource does not appear in a data base, it is set to $0 . E_{\text {tax_dist }}$ is a variable with values within the interval $[0,1]$. It is defined by the following equation:

$E_{\text {tax_dist }}=1-\frac{\text { steps in tree }}{\text { maximum step } \text { sin tree }}$

The ratio on the right side is the ratio between the steps in the tree-graph that describes the taxonomy to reach one waste / resource from another, divided by the maximum number of non-recurring steps to reach two concepts in the graph. One can easily see that if a concept is identical, the number of steps is 0 , leading to a value of 1 for $E_{\text {tax_dist }} . E_{\text {comp }}$ is binary. If a component of a waste / resource matches another waste / resource, the value is set to 1 . If no component matches another waste / resource, it is 0 .

All matches are ranked with respect to the score and a threshold value is defined for only selecting the most promising potential symbioses. Once all matches have been identified, based on the model of the industrial zone, the actual eco-industrial park architectures are generated, which will be described in the next section.

\section{GENERATING PARETO-OPTIMAL ECO-INDUSTRIAL PARK ARCHITECTURES}

For generating "good" eco-industrial park architectures, we need to define the objective functions, variables, and constraints. We say "good" instead of "optimal", as we are dealing with a multi-objective optimization problem where trade-offs between economic and environmental performance have to be made. Hence, an increase in economic performance usually has to be traded against decreasing environmental performance. The multi-objective optimization problem is formulated as:

$$
\max \left(\begin{array}{c}
\Delta p_{\text {tot }} \\
S
\end{array}\right)
$$

$$
\text { subject to } \begin{aligned}
\dot{m}_{\text {supply }_{i j p}}-\min \left(\dot{m}_{\text {supply_max }_{i j p},} \dot{m}_{\text {demand_max }_{i j p}}\right) \leq 0 \\
\dot{m}_{\text {supply }_{i j p}} \geq 0
\end{aligned}
$$

We will introduce each of the terms in the following. We use two objective functions. The first objective function seeks to maximize the economic performance of the eco-industrial park $\Delta p_{t o t} . \Delta p_{t o t}$ indicates the profit from implementing the eco-industrial park. The second objective function seeks to maximize the environmental performance $S$ for an eco-industrial park.

Currently, there are two types of inequality constraints. The first inequality constraint states that a waste / resource stream $\dot{m}_{\text {supply }}$ between two plants $i$ and $j$ of type $p$ cannot exceed either the maximum supply $\dot{m}_{\text {supply_max }}$ ijp of a plant $i$ or the maximum demand $\dot{m}_{\text {demand_max }}{ }_{i j p}$ of a plant $j$. In other words, the waste / resource stream cannot be larger than what the receiver needs and cannot be larger than what the supplier can supply. We take the minimum of the two values, as the minimum value is the constraining value. The other, trivial type of constraint is that the waste / resource flow cannot be smaller than 0 .

The economic performance is calculated for all symbiosis supplier and receiver pairs and their specific waste / resource flow identified in the matchmaking step. The economic performance is expressed as the difference between the situation without the symbiosis and the situation with the symbiosis. We call the situation without the symbiosis the "counterfactual situation". For the supplier side, the counterfactual situation is described by the equation:

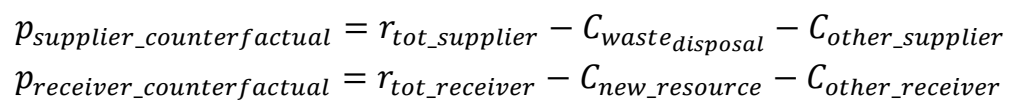

For the supplier, the profit $p_{\text {supplier_counterfactual }}$ is the difference between the revenue $r_{\text {tot_supplier }}$ and the cost of waste disposal $C_{\text {waste }}$ disposal and other costs for the plant $C_{\text {other_supplier }}$. For the receiver, the profit $p_{\text {receiver_counterfactual }}$ is the difference between the revenues $r_{\text {tot_receiver }}$ and the price for acquiring the new resources $C_{\text {new_resource }}$ plus other costs of the plant $C_{\text {other_receiver }}$. The situation with the symbiosis can be formulated as following:

$p_{\text {supplier_symb }}=r_{\text {tot_supplier }}+r_{\text {symb_supplier }}-C_{\text {symbiosis_supp }}-C_{\text {other_supplier }}$ 
$p_{\text {receiver_symb }}=r_{\text {tot_receiver }}+r_{\text {symb_receiver }}-C_{\text {symbiosis_rec }}-C_{\text {other_receiver }}$

$p_{\text {supplier_symb }}$ is the profit of the supplier with the symbiosis. $p_{\text {receiver_symb }}$ is the profit of the receiver with the symbiosis. $r_{\text {symb_supplier }}$ is the revenue from the symbiosis for the supplier and $r_{\text {symb_receiver }}$ is the revenue from the symbiosis for the receiver. The costs incurred by the symbiosis are represented by $C_{\text {symbiosis_supp }}$ for the supplier and $C_{\text {symbiosis_rec }}$ for the receiver. Note that the underlying assumption is that the cost of the symbiosis and its revenues can be separated from other revenues and costs of the plant. We can imagine cases where the substitute has an inferior quality compared to the new resource and hence leads to a product with inferior quality. This may affect the overall revenue from the product produced by the receiver. The assumption of separability greatly simplifies the economic assessment of industrial symbioses. On the downside, it does not take into account potential savings or additional costs from changed internal processes of industrial plants.

$$
\begin{aligned}
& \Delta p_{\text {supplier }}=p_{\text {supplier }} \text { symb }_{\text {supplier }}-p_{\text {counterfactual }}=r_{\text {symb }} \text { supplier }-C_{\text {symbiosis } \text { supp }_{\text {suste }}}+C_{\text {wisposal }} \\
& \Delta p_{\text {receiver }}=p_{\text {receiver }_{\text {symb }}}-p_{\text {receiver }_{\text {counterfactual }}}=r_{\text {symb }} \text { receiver }-C_{\text {symbiosis_rec }}+C_{\text {new_resource }}
\end{aligned}
$$

The total profit from all suppliers and receivers results in:

$$
\Delta p_{\text {tot }}=\Delta p_{\text {receiver }}+\Delta p_{\text {supplier }}
$$

Decomposing the left-hand side into its elements leads to the following equation, which is in essence the standard formula for calculating the Net Present Value (NPV) of the investment in the set of symbioses:

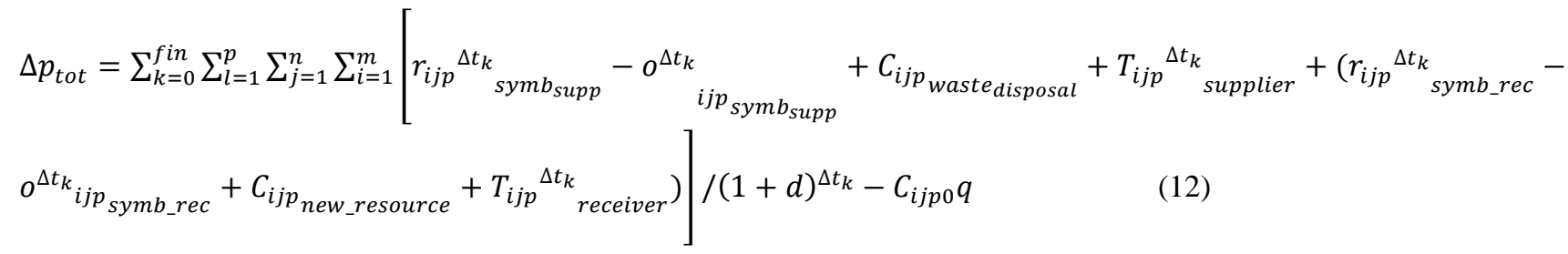

$r_{i j p}{ }^{\Delta t_{k}}{ }_{\text {symb } b_{\text {supp }}}$ and $r_{i j p}{ }_{\text {symb_rec }}$ are revenues from the supplier and receiver side due to the symbiosis $\mathrm{p}$ between plants $\mathrm{i}$ and $\mathrm{j}$ in a time-period $\Delta t_{k} \cdot o^{\Delta t_{k}}{ }_{i j p}$ are the operational expenses for a symbiosis $\mathrm{p}$ between plants $\mathrm{i}$ and $\mathrm{j}$. Note that the expression in the bracket [] is the in- and out-flow of capital from the set of symbioses. The expression in the bracket () is the time-value of capital, expressed by the interest rate $d$ for the time period $\Delta t_{k} . C_{i j p 0}$ are the capital expenditures for the symbioses. $q$ is the fraction of the capital expenditures that would be paid by the companies participating in the symbiosis. A certain percentage of the capital expenditures could be paid by governmental agencies or other institutions.

Estimating environmental performance is in general challenging. As a first step, we use a waste reduction / resource substitution indicator. The indicator is based on the amount of waste that is avoided within an eco-industrial park and the amount of resources that is substituted by wastes. For each symbiosis $s$ with a resource $k$ between two plants $i$ and $j$, we have a substitution factor $c_{p q}$. The substitution factor is 1 , if the amount of new resource replaced by the waste is equal to the amount of waste. $c_{p q}$ is selected accordingly if more or less new resources are substituted by the symbiosis. Hence, a simple environmental performance indicator can be written as:

$S=S_{\text {resources }}+S_{\text {waste }}=\sum_{i=1}^{m} \sum_{j=1}^{n} S_{i j p_{-} \text {resource }}+s_{i j p_{-} \text {waste }}=\sum_{i=1}^{m} \sum_{j=1}^{n} s_{i j p_{\text {waste }}}\left(1+c_{p q}\right)$

Where $S_{\text {resources }}$ is the total amount of new resources saved and $S_{\text {waste }}$ is the amount of wastes that does not need to be treated. To give an example for the substitution factor $c_{p q}$, only about $5 \%$ of biomass can be converted to hydrogen via existing conversion processes. In that case, $s_{i j p \_w a s t e}$ would be the amount of biomass that is converted and $s_{i j p \_r e s o u r c e}$ the amount of hydrogen substituted. Hence, we can substitute $s_{i j p \_r e s o u r c e}$ by a conversion factor $c_{p q}$ between the waste stream $p$ and the resource stream $q$ after conversion, multiplied by $s_{i j p_{\text {waste }}}$.

With the optimization problem formulated, we can now select an appropriate multi-objective optimization algorithm. The problem has multiple objectives, linear objective functions, and linear constraints. We use a standard multi-objective genetic algorithm for solving 
the optimization problem, as the algorithm is flexible enough for coping with potential non-linear extensions of the current optimization problem.

After having formulated the matchmaking approach and optimization problem, in the next step, we apply the methodology to an existing eco-industrial park case study.

\section{CASE STUDY: KALUNDBORG ECO-INDUSTRIAL PARK}

We use a retrospective case study for validating if the methodology is capable of reproducing at least some of the existing symbioses in an eco-industrial park. Furthermore, we compare the optimal solution to the existing eco-industrial park architecture. We choose the Kalundborg eco-industrial park as the retrospective case study, due to the amount of data available, compared to other eco-industrial parks, and its archetypical character. We selected the most relevant six plants in the park: the Asnaes coal-fired power plant, the Statoil refinery, the Novo Nordisk pharmaceutical plant, the Kalundborg municipality, local farmers, and a cement company.

Table 2 shows the identified symbiosis opportunities by the matching algorithm. The right column shows if there is a corresponding existing symbiosis in the Kalundborg eco-park. Some of the symbioses detected by the matchmaking algorithm do not exist in reality. This result can be explained by the difficulties of implementing industrial symbioses practically, as a number of additional criteria have to be met. Hence, only a small subset of possible symbioses is actually implemented in reality.

Table 2: Some results of the matching algorithm for the Kalundborg eco-industrial park

\begin{tabular}{|l|l|l|l|}
\hline $\begin{array}{l}\text { Symbosis } \\
\text { partner: } \\
\text { supplier }\end{array}$ & $\begin{array}{l}\text { Symbiosis } \\
\text { partner: } \\
\text { receiver }\end{array}$ & $\begin{array}{l}\text { Material } \\
\text { I energy } \\
\text { flow }\end{array}$ & $\begin{array}{l}\text { Corresponding } \\
\text { existing } \\
\text { symbiosis? }\end{array}$ \\
\hline Refinery & Pharmaceutical & Steam & No \\
\hline Refinery & Municipality & Steam & No \\
\hline Refinery & Power plant & $\begin{array}{l}\text { Waste } \\
\text { water }\end{array}$ & Yes \\
\hline Pharmaceutical & Power plant & $\begin{array}{l}\text { Waste } \\
\text { water }\end{array}$ & No \\
\hline Pharmaceutical & Farmers & Sludge & Yes \\
\hline Municipality & Power plant & $\begin{array}{l}\text { Waste } \\
\text { water }\end{array}$ & No \\
\hline Power plant & Refinery & Steam & Yes \\
\hline Power plant & Pharmaceutical & Steam & No \\
\hline Power plant & Municipality & Steam & Yes \\
\hline Power plant & $\begin{array}{l}\text { Cement } \\
\text { company }\end{array}$ & Fly ash & Yes \\
\hline Power plant & Farmers & Sludge & No \\
\hline Cement plant & Farmers & Sludge & No \\
\hline
\end{tabular}

Fig. 7 shows the graph for all detected potential symbioses between a set of industrial plants and the municipality of Kalundborg.

Some of the symbioses that exist in reality were not detected:

- $\quad$ Flare gas: Refinery - power plant

- Yeast slurry: Pharmaceutical - pig farms

In both cases, the waste / resource pairs were not detected, as they were more specific than the meta-models used. For example, yeast slurry is generated in pharmaceutical plants producing insulin. The meta-model of the pharmaceutical plant used is a generic pharmaceutical plant and hence, yeast slurry as a waste was not included in the model. Flare gas was not detected, as the amount of gas produced is small and furthermore not produced continuously. Hence, it was not listed in the meta-model as a relevant waste from a refinery. Therefore, the two symbioses were not detected due to the lack of detail and specificity of the meta-models. This is an important underlying hypothesis. This means if one wants a more refined symbiosis matching there is a need for further data gathering and refined modeling of the industrial zone. 


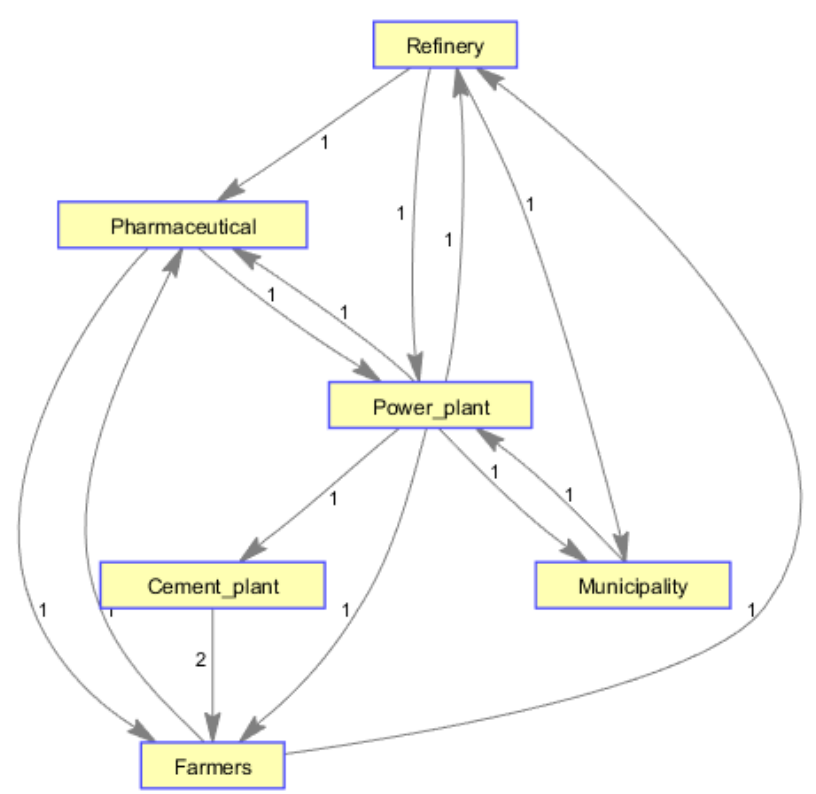

Fig. 7: Graph of all detected potential symbioses between industrial plants and municipality at Kalundborg (edge numbers indicate number of symbioses between industrial plants)

After the matchmaking step, the genetic algorithm was used for generating eco-industrial park architectures and finding Pareto-optimal architectures. Fig. 8 shows the set of generated eco-industrial park architectures, evaluated with respect to the NPV after 6 years and the amount of resources substituted. The NPV was calculated for 6 years, as none of the architectures for 5 years created a positive NPV. Hence, the breakeven point for the generated architectures is 5 years. The question is if this also related to actual deployment in Kalundborg. This question could not be answered at this point, as financial data from the eco-park is not available. Future work would develop financial estimates, based on the data for the existing symbiosis. As the quantities for material flows are known and their market prices, rough estimates for the economic performance of Kalundborg can be developed. For the environmental performance of the generated architectures, no conversion was involved between the symbiosis partners and hence, the total resources substituted equals the amount of waste avoided.



Fig. 8: Six Pareto-optimal eco-industrial park architectures evaluated with respect to NPV and resources substituted

Table 3 shows the amount of wastes / resources exchanged per year for each of the potential symbioses for the Pareto-optimal solution, indicated as the red line in Fig. 8. It shows that the steam generated by the refinery is shared between the pharmaceutical plant and the 
municipality. Furthermore, the power plant receives waste water from two different suppliers, the refinery and the pharmaceutical plant. The farmers receive sludge from two suppliers as well: the power plant and cement plant.

Table 3: Amount of wastes / resources exchanged between the symbiosis partner for the Pareto-optimal solution

\begin{tabular}{|l|l|l|r|}
\hline $\begin{array}{l}\text { Symbosis } \\
\text { partner: } \\
\text { supplier }\end{array}$ & $\begin{array}{l}\text { Symbiosis } \\
\text { partner: } \\
\text { receiver }\end{array}$ & $\begin{array}{l}\text { Material } \\
\text { energy flow }\end{array}$ & $\begin{array}{l}\text { Amount of } \\
\text { resources } \\
\text { [t/a] }\end{array}$ \\
\hline Refinery & $\begin{array}{l}\text { Pharmaceuti } \\
\text { cal }\end{array}$ & Steam & 1200 \\
\hline Refinery & Municipality & Steam & 94,090 \\
\hline Refinery & Power plant & Waste water & 467,390 \\
\hline $\begin{array}{l}\text { Pharmaceuti } \\
\text { cal }\end{array}$ & Power plant & Waste water & 154,890 \\
\hline $\begin{array}{l}\text { Pharmaceuti } \\
\text { cal }\end{array}$ & Farmers & Sludge & 23,040 \\
\hline Municipality & Power plant & Waste water & 74,130 \\
\hline Power plant & Cement plant & Fly ash & 500 \\
\hline Power plant & Farmers & Sludge & 23,000 \\
\hline $\begin{array}{l}\text { Cement } \\
\text { plant }\end{array}$ & Farmers & Sludge & 2070 \\
\hline Farmers & Refinery & Methane & 6310 \\
\hline Farmers & $\begin{array}{l}\text { Pharmaceuti } \\
\text { cal }\end{array}$ & Methane & 6670 \\
\hline
\end{tabular}

The Kalundborg case study has demonstrated that the methodology is able to reproduce part of the existing symbioses and is furthermore able to create Pareto-optimal eco-industrial park architectures.

\section{CONCLUSIONS}

This paper presented a methodology for finding potential symbioses under insufficient data and generating eco-industrial park architectures based on the symbioses with the highest feasibility likelihood. The methodology was demonstrated by its application to an existing eco-industrial park at Kalundborg. The application to the case study showed that most of the existing symbioses could be detected. The ones not detected were not detected due to the lack of a sufficiently detailed industrial plant meta-models and a lack of variety of plants represented in the meta-model taxonomy. Future work will focus on testing alternative scoring approaches for the potential symbioses after matchmaking and extending the environmental performance indicator to a LCA appraoch. The methodology needs to be further validated on existing and planned eco-industrial parks.

\section{REFERENCES}

Boons, F., Spekkink, W., 2012. Levels of institutional capacity and actor expectations about industrial symbiosis. J. Ind. Ecol. 16, 6169.

Brown, H., 1996. Energy analysis of 108 industrial processes. Fairmont Press Inc.

Cecelja, F., Raafat, T., Trokanas, N., Innes, S., Smith, M., Yang, A., Zorgios, Y., Korkofygas, A., Kokossis, A., 2015. e-Symbiosis: technology-enabled support for Industrial Symbiosis targeting Small and Medium Enterprises and innovation. J. Clean. Prod. 98, 336-352.

Chertow, M. R., Lombardi, D.R., 2005. Quantifying economic and environmental benefits of co-located firms. Environ. Sci. Technol. $39,6535-6541$.

Condat, H., Strobel, C., Hein, A., 2012. Model-based automatic generation and selection of safe architectures. INCOSE Int. Symp. 22, $612-632$.

Deutz, P., 2014. Food for Thought: Seeking the Essence of Industrial Symbiosis, in: Salomone, R., Saija, G. (Eds.), Pathways to Environmental Sustainability. Springer, pp. 3-11.

Gertler, N., 1995. Industry ecosystems: developing sustainable industrial structures. Maters' Thesis, Massachusetts Institute of Technology. 
Grant, G., Seager, T., 2010. Information and communication technology for industrial symbiosis. J. Ind. Ecol. 14, 740-753.

Hein, Jankovic, M., Farel, R., Lei, I.S., Yannou, B., 2015a. Modeling Industrial Symbiosis Using Design Structure Matrices, in: 17th International Dependency and Structure Modeling Conference, DSM 2015. Fort Worth, Texas, USA.

Hein, Jankovic, M., Farel, R., Yannou, B., 2015b. A Conceptual Framework for Eco-Industrial Parks, in: Proceedings of the ASME 2015 International Design Engineering Technical Conferences \& Computers and Information in Engineering Conference IDETC/CIE 2015. pp. 987-988.

Hein, A., 2010. Identification and Bridging of Semantic Gaps in the Context of Multi-Domain Engineering, in: Abstracts of the 2010 Forum on Philosophy, Engineering \& Technology.

Hodge, M., Ochsendorf, J., Fernández, J., 2010. Quantifying potential profit from material recycling: A case study in brick manufacturing. J. Clean. Prod. 18, 1190-1199.

Inspection des Installations Classées, 2015. Base des Installations Classées [WWW Document]. URL http://www.installationsclassees.developpement-durable.gouv.fr/

Jacobsen, N.B., 2006. Industrial Symbiosis in Kalundborg, Denmark: A Quantitative Assessment of Economic and Environmental Aspects. J. Ind. Ecol. 10, 239-255.

Julien-Saint-Amand, F., Le Moenner, P., 2008. Industrial Ecology, an Innovative Approach Serving Spatial Planning: the Example of the Tool PRESTEO@(A Program to Research Synergies on a Territory), in: 6th International Conference of Territorial Intelligence" Tools and Methods of Territorial Intelligence.

Korhonen, J., Snäkin, J.P., 2005. Analysing the evolution of industrial ecosystems: Concepts and application. Ecol. Econ. 52, $169-186$.

Lowe, E.A., 2001. Eco-industrial park handbook for Asian developing countries. Indigo Development.

Massard, G., Erkman, S., 2007. A regional industrial symbiosis methodology and its implementation in Geneva, Switzerland. 3rd Int. Conf. Life Cycle Manag. 27, 29.

Miller, G., 1956. The magical number seven, plus or minus two: some limits on our capacity for processing information. Psychol. Rev. 63,81 .

Schulze, F., 2014. Classification and development of mathematical models and simulation for industrial ecology. Masters' Thesis, University of Rhode Island.

Sokka, L., 2011. Local systems, global impacts: Using life cycle assessment to analyse the potential and constraints of industrial symbioses. VTT Publ. 1-158.

Tian, J., Zelkowitz, M. V., 1992. A formal program complexity model and its application. J. Syst. Softw.

Zamagni, A., Guinée, J., Heijungs, R., Masoni, P., Raggi, A., 2012. Lights and shadows in consequential LCA. Int. J. Life Cycle Assess. 17, 904-918. 